Gut, 1978, 19, 831-837

\title{
Selective transplenic decompression of oesophageal varices by distal splenorenal and splenocaval shunt
}

\author{
R. A. BHAlERAO, A. C. PINTO, R. D. BAPAT, S. V. SHETTY, P. D. BHide, \\ V. S. WAINGANKAR, J. M. KIRTANE, V. G. MEHENDALE, AND \\ S. D. SHETTY
}

From King Edward VII Memorial Hospital, Parel, Bombay, India

SUMMARY The usefulness of selective transplenic decompression of oesophageal varices by distal splenorenal shunt and splenocaval shunt was evaluated in the control of gastrointestinal haemorrhage in patients with portal hypertension of varied aetiology. (Decompression was successful in 69 out of 78 cases.) It was shown that it is superior to total portosystemic shunts, as the incidence of encephalopathy was very low compared with the data from our series of portocaval shunts. The operative mortality has been progressively lowered and has now reached levels comparable with portocaval shunt. Distal splenorenal shunt when performed as an emergency procedure to arrest bleeding has limited usefulness but when performed as an elective or prophylactic procedure its results are comparable with those of portocaval shunt without the untoward complications such as encephalopathy. A modified selective decompression of varices has been described in which the distal end of the splenic vein is anastomosed to the inferior vena cava. Though no long term follow-up studies are available, we believe that this shunt is likely to prove superior to distal splenorenal shunt as it has both the advantages of the distal splenoral and the haemodynamic advantage of end-to-side portocaval shunt. We conclude that in patients with portal hypertension of varied aetiology, who have not had a haemorrhagic episode but in whom varices have been demonstrated or who have had one episode of haemorrhage from varices, the splenocaval shunt when feasible or the distal splenorenal shunt offers the optimal method of management at present in India.

From 1973 to 1977 an attempt was made in a series of 78 cases of portal hypertension with oesophageal varices selectively to decompress the varices by distal splenorenal or splenocaval shunt. Of these 78 cases, in nine the splenorenal shunt was not feasible as the splenic vein was unsuitable for anastomosis, while in the remaining 69 cases the shunt was successfully constructed.

We had attempted distal splenorenal shunt as early as 1968 (Warren et al., 1967), but after five unsuccessful cases it was given up. After the report of distal splenorenal shunt in 1972 by Warren et al. (Warren et al., 1972, 1974; Thomford et al., 1975) we once again focused our attention on this shunt; hitherto, end-to-side portocaval shunt was the procedure of choice (and is still done in cases where the splenic vein is diseased). Seventy-three cases of portal hypertension with oesophageal varices were treated by end-to-side portocaval shunt from 1965 to 1977 .

Received for publication 12 May 1978
A newer modification whereby, in 15 cases, the splenic vein was anastomosed to the side of the inferior vena cava instead of the renal vein is also included in this series of 69 shunts.

In the present study we attempt to evaluate the effectiveness of splenorenal shunt in controlling gastrointestinal haemorrhage due to portal hypertension of varied aetiology.

\section{Methods}

In 69 cases, extrahepatic portal hypertension due to cavernoma was present in 17 , primary portal hypertension or non-cirrhotic fibrosis in 14, while in the remaining 38 cases cirrhosis of the liver was the cause of the portal hypertension. The present study includes 10 patients in the paediatric age group (less than 12 years old). The youngest patient in the series was 5 years old, and the oldest was 55 years (Table 1). There were 50 male and 19 female patients. Fourteen patients presented with a lump in the abdomen, 48 had a history of gastrointes- 
Table 1 Age incidence

\begin{tabular}{ll}
\hline Age $(y r)$ & No. of cases \\
\hline Paediatric age group & \\
up to 12 & 10 \\
12 to 20 & 20 \\
21 to 40 & 28 \\
41 onwards* & 11 \\
\hline
\end{tabular}

*Oldest patient 55 yr.

tinal haemorrhage, and seven were admitted with haematemesis. These seven patients underwent emergency splenorenal shunt for control of variceal bleeding after balloon tamponade had failed to arrest haemorrhage. In other cases surgery was performed as an elective planned procedure.

PREOPERATIVE ASSESSMENT

A general assessment of the patient's condition was carried out, particular attention being paid to the evaluation of hepatic and renal function. The nutritional status was also evaluated, an aspect of preoperative assessment which is of particular importance in India.

Percutaneous splenoportography was performed in all cases to determine the portal pressure, assess the patency of the splenic and portal veins, and define their anatomical relationship. Even in those cases where splenorenal shunt was done as an emergency procedure, splenoportography was undertaken with temporary control of bleeding by means of balloon tamponade.

Patients who presented with ascites at the time of admission were put on diuretics and the ascites was thereby controlled before surgery.

\section{OPERATIVE MANAGEMENT}

A long midline incision was taken from xiphisternum to about $5 \mathrm{~cm}$ below the umbilicus. Initially, a straight midline incision was employed, but we later modified our incision to a valvular incision in which the skin was incised to the left of the midline but the peritoneum was incised well to the left of the midline together with transversus abdominis muscle after incision of the left rectus sheath and retraction of the left rectus muscle. This prevented leakage of ascitic fluid, which is a common problem in postoperative management.

The peritoneal cavity having been opened, exploration of the abdominal viscera was quickly undertaken, avoiding damage to vascular adhesions if present. The liver was inspected and a wedge liver biopsy taken.

The small bowel was isolated in gauze sponge outside the abdominal cavity and the transverse colon retracted upwards. An incision was made in the posterior peritoneum at the level of the inferior mesenteric vein. The vein was traced cephalad towards its drainage into the splenic vein so as to facilitate the identification of the splenic vein which lies embedded in the inferior border of the pancreas. The inferior, superior, and posterior aspects of the splenic vein were cleared for 3.75 to $5 \mathrm{~cm}$. The dissection was facilitated by injection of saline into the tissues around the vein. The hydrostatic force lifted the soft tissues away from the vein, which could be easily dissected off without fear of damaging the vein wall and, at the same time, the small pancreatic tributaries were well defined. This was not possible if the vein were diseased or if there were an atheromatous plaque. An attempt was now made to free the splenic vein from the pancreatic bed at one place. The greatest care was exercised while trying to dissect the vein away from the pancreas, because small pancreatic tributaries which enter the splenic vein could cause troublesome bleeding. Injection of saline helped in the gentle dissection of the pancreatic tributaries, which were doubly ligated in continuity before being divided.

Once the splenic vein was 'looped around', further dissection was easy. The dissection of the splenic vein was continued medially until sufficient length was available for anastomosis. There are fewer pancreatic tributaries near the mesenteric end of the splenic vein where it is joined by the superior mesenteric vein to the right of the superior mesenteric artery in front of the third part of duodenum. Thus the splenic vein was dissected free for about 3.75 to $5 \mathrm{~cm}$, as medially as possible. The left gastric vein usually required ligation. Once the splenic vein was ready for anastomosis, attention was turned to dissection of the left renal vein. The duodenum needed to be mobilised by cutting the ligament of Treitz at an earlier stage of the operation. The left renal vein was identified by blunt dissection behind the third part of duodenum. The vein was dissected along its whole length. In the majority of cases it was desirable to divide the suprarenal as well as the gonadal veins in order to achieve better mobility of the vein, so that the venous anastomosis could be achieved without tension.

When the dissection of the splenic and renal veins was completed, the type of venovenous anastomosis to be contemplated depended upon the gross approximation of both veins that could be achieved and the dissected length of splenic vein that was available. The choice of site of the venovenous anastomosis to renal vein was most important, in order that no angulation should occur in the anastomosis. 
In our series of 69 cases (Table 2), end-splenic-toside renal anastomosis was constructed in 25 cases, end-renal-to-side splenic in nine cases (with ligature of the hepatic end of the splenic vein), in 20 cases end-splenic-to-end renal anastomosis was done, while in the remaining 15 cases the splenic vein was anastomosed to the side of the inferior vena cava. The splenic vein was divided close to its junction

Table 2 Results of different shunts

\begin{tabular}{|c|c|c|c|c|}
\hline Type of shunt & $\begin{array}{l}\text { Total } \\
\text { no. of } \\
\text { cases }\end{array}$ & Alive & $\begin{array}{l}\text { Survival } \\
(\%)\end{array}$ & $\begin{array}{l}\text { Statistical } \\
\text { significance }\end{array}$ \\
\hline $\begin{array}{l}\text { End renal vein to } \\
\text { side splenic vein } \\
\text { (with ligature on } \\
\text { hepatic side of } \\
\text { splenic vein) }\end{array}$ & 9 & 6 & $66 \cdot 6$ & NS \\
\hline $\begin{array}{l}\text { End splenic vein to } \\
\text { side renal vein } \\
\text { End renal vein to }\end{array}$ & 25 & 15 & $60 \cdot 0$ & NS \\
\hline $\begin{array}{l}\text { end splenic vein } \\
\text { Lienocaval shunt }\end{array}$ & $\begin{array}{l}20 \\
15\end{array}$ & $\begin{array}{l}12 \\
12\end{array}$ & $\begin{array}{l}60 \cdot 0 \\
80 \cdot 0\end{array}$ & $\begin{array}{l}\text { NS } \\
\text { NS }\end{array}$ \\
\hline
\end{tabular}

NS: not significant.

with the superior mesenteric, tying off the hepatic end, while the renal vein was divided near the hilum of the kidney in end-splenic to end-renal venovenous anastomosis. In adults, we used 6-0 arterial silk with continuous anterior and posterior layer suture, while in children we used an anterior and posterior interrupted row of sutures for anastomosis to allow the shunt to grow with the rest of the body. Later in our series (Fig. 1), we attempted a modified technique in which the splenic end of the splenic vein was anastomosed to the inferior vena cava at its left lateral margin just below the opening of the left renal into the inferior vena cava. Depending upon the dissected length of splenic vein that was available and the feasibility of approximating it with the inferior vena cava without tension, we felt that this would be haemodynamically a superior shunt to splenorenal. The size of the splenic vein was then the sole factor which determined the size of the shunt; in this way limitations imposed by the diameter of the renal vein were excluded and construction of a larger shunt was made possible. This, we hoped, would overcome the increased incidence of blocked shunt in distal splenorenal shunts. An ellipse was cut from the left lateral margin of the inferior vena cava and an anastomosis was constructed between the inferior vena cava and the splenic vein, in a manner similar to that of portocaval shunt.

After haemostasis was achieved, attention was turned to devascularisation of the stomach. The left gastric vessels were ligated near the lesser

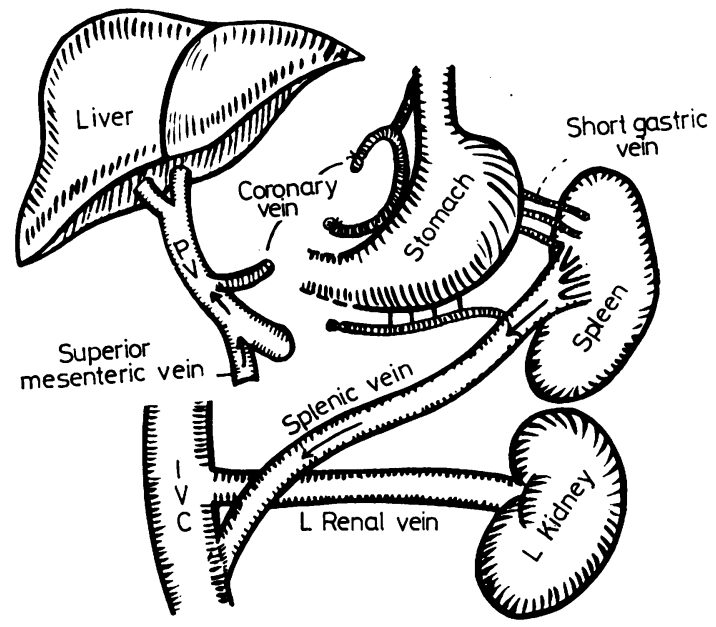

Fig. 1 Diagram of lienocaval shunt.

curvature of the stomach and the right gastroepiploic vessels were ligated in continuity near the pyloroduodenal junction. Initially, in seven cases, we did not carry out this devascularisation, but we learned our lesson after we lost one patient because erosion of a left gastric varix caused gastrointestinal haemorrhage in the postoperative period.

\section{Results}

SURVIVAL

Out of 69 cases, 45 patients are alive, giving a survival rate of $65.2 \%$. However, out of these there were six late deaths, of which one was due to serum hepatitis, while the rest died of haematemesis following a blocked shunt. This included one patient who died of haematemesis from erosion of the left gastric varix where devascularisation was not done. There were 24 hospital deaths in our series. However, as shown in Table 2, the results of the various lienorenal shunts do not differ significantly.

The longest survival we have in our series is four years and the patient is still well.

\section{PATENCY}

The patency of the splenorenal shunts was determined postoperatively by means of splenography in the survivors, or at necropsy (Fig. 2). Forty out of 45 patients demonstrated patent shunts, while, in two of the 24 deaths, thrombosis of the shunt was revealed at necropsy. Thus we have a patency rate of $89.7 \%$, which is superior to the patency rate of conventional splenorenal shunt. 

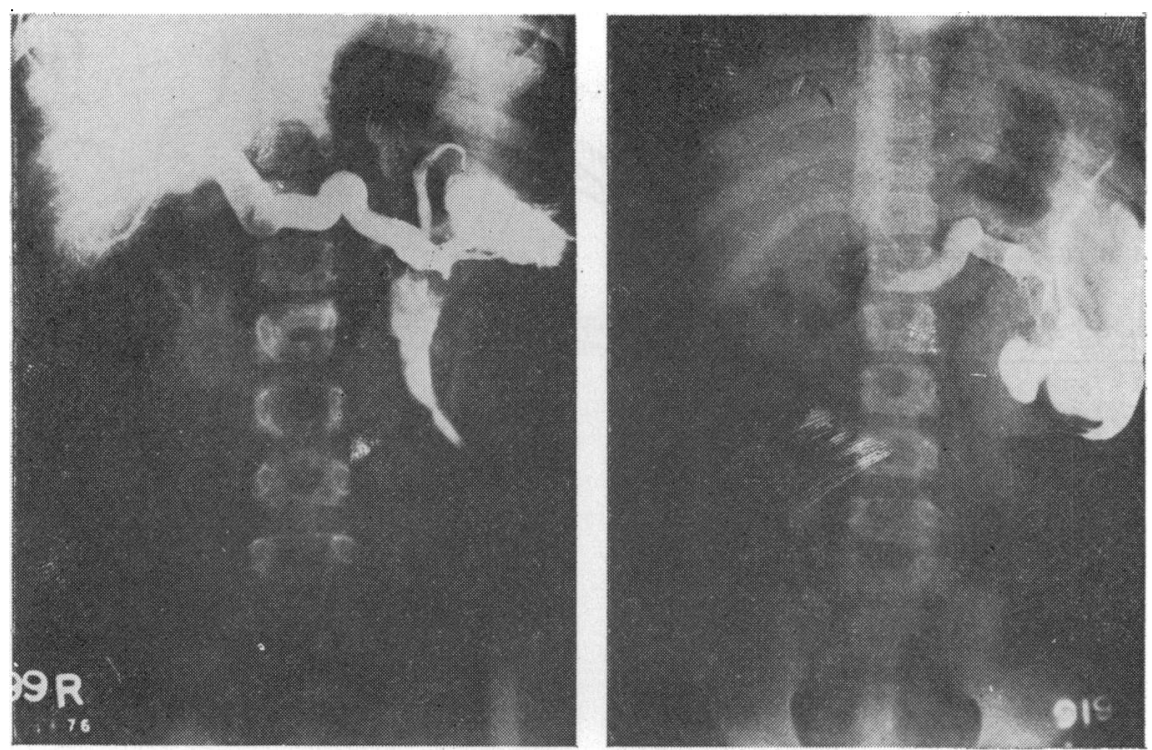

\section{ENCEPHALOPATHY}

A problem closely related to metabolic efficiency in patients following shunt procedures is that of encephalopathy. So far, no patient has been admitted to the hospital with symptoms related to encephalopathy over a period of four years, in contrast to the high incidence in the portocaval series.

The occurrence of encephalopathy in our new modification of splenocaval shunt is open to question, but so far, in the longest follow-up of $1 \frac{1}{2}$ years, we have had no patient coming back with encephalopathy; hence it would be reasonable to assume that the incidence of encephalopathy will be as low as in distal splenorenal shunt, as it is apparent that the incidence is highest in the first one to two years, as judged from our portocaval series.

\section{EFFECTIVENESS OF DECOMPRESSION (Fig. 3)}

The demonstration of a patent shunt does not in itself indicate that gastrointestinal haemorrhage will be effectively prevented, but regular clinical follow-up of these patients over a prolonged period of time will tell. There have been five instances of late rebleeding due to oesophageal varices. Of these, in four patients the shunt was blocked as demonstrated angiographically.

In the remaining living patients, no one was admitted with rebleeding from varices.

\section{Discussion}

In analysing our data of series of distal splenorenal shunts, a few salient features should be considered.
We have a series of near equal numbers of both types--that is, we have 73 cases of portocaval shunt with which comparison could be made.

In understanding surgical therapy for bleeding gastrointestinal varices by shunt procedures, it is important to note that the result of any new procedure should be compared with the time-honoured portocaval shunt, which has stood the test of time and is still popular in many centres round the world.

The Dean Warren shunt is technically a more difficult procedure than portocaval shunt. The availability of good healthy splenic vein is the most important prerequisite for splenorenal shunt. The splenic vein may appear normal on angiography but on the operating table it may be found to be diseased-for example, riddled with plaques and thrombi-so that the surgeon is forced to abandon the shunt, as we had to do in nine cases.

The splenic vein, being embedded in pancreas, is difficult to mobilise and if the pancreas is affected by chronic pancreatitis it constitutes an additional hazard in the construction of the shunt. The operative time is the crucial factor, for an average of $2 \frac{1}{2}$ hours is required for portocaval shunt. The splenorenal shunt takes about $4 \frac{1}{2}$ to five hours, thus subjecting poor-risk cirrhotic patients to excessive metabolic and anaesthetic strain.

The Dean Warren splenorenal shunt as an emergency procedure (Table 3 ) appears to be inadequate, as our mortality is $85.7 \%$ (one out of seven is alive) and all these patients have succumbed finally to gastrointestinal haemorrhage in spite of patent 


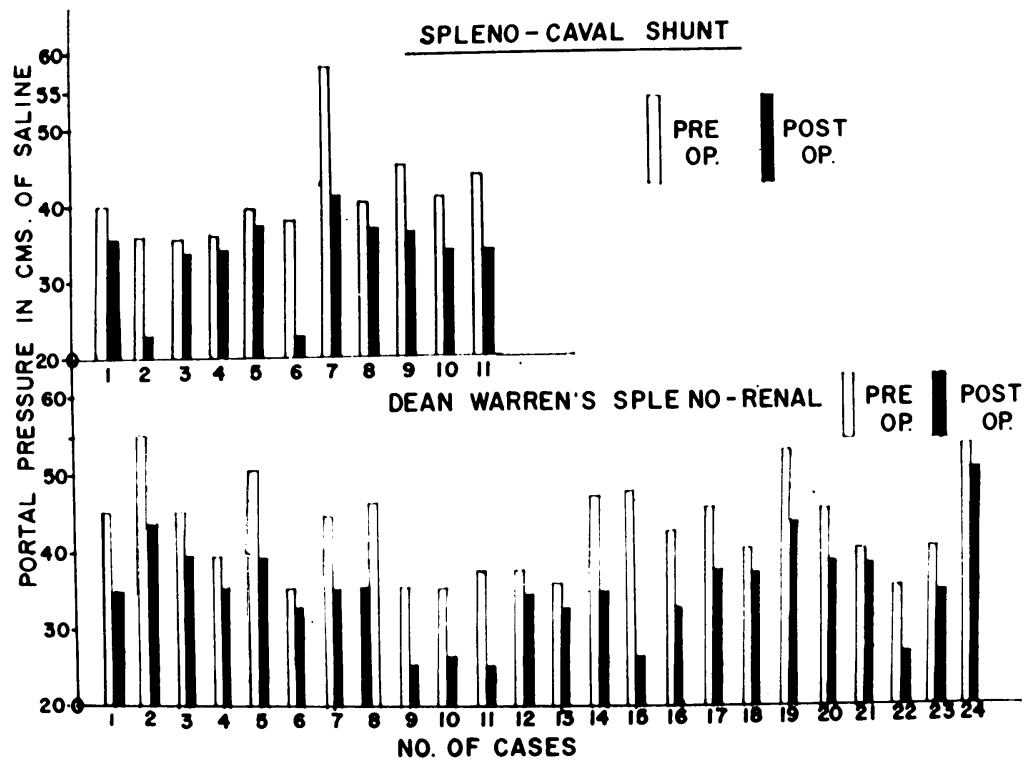

Fig. 3 Pre- and post-shunt portal pressure in splenorenal and lienocaval shunts taken after six weeks.

Table 3 Comparison between Dean Warren and portocaval shunt performed as emergency shunt

\begin{tabular}{cllll}
\hline Liver & Operation & \multicolumn{2}{c}{ No. of cases } & $\begin{array}{l}\text { Mortality } \\
(\%)\end{array}$ \\
\cline { 3 - 4 } & & Total & Alive & \\
\hline $\begin{array}{c}\text { Smooth } \\
\text { PPH }\end{array}$ & DW & - & - & \\
EHO & PCS & - & - & \\
DW & PCS & - & - & \\
Granular & & & & \\
& & & & \\
& DW & 5 & nil & \\
Total & PCS & 29 & 9 & \\
& DW & & $(1$ LD) & \\
& PCS & 29 & 1 & 85.7 \\
\hline
\end{tabular}

PPH: primary portal hypertension. EHO: extrahepatic obstruction. DW: Dean-Warren. PCS: portocaval shunt. LD: late death.

shunt at necropsy. Perhaps more extensive devascularisation or direct ligation of varices in addition to the shunt would be effective. In contrast, in our portocaval shunt series, the mortality is $69.0 \%$ (nine alive out of 29). However, no patient died of gastrointestinal haemorrhage, thus proving the superiority of this shunt over splenorenal shunt, in which decompression is inadequate to stop the haemorrhage.

In the cirrhotic patient and in the group with primary portal hypertension, as an elective and prophylactic procedure the immediate hospital mortality in selective shunts is $31.9 \%$ (32 alive out of 47 ) as against $20.5 \%$ (35 alive out of 44 ) in the portocaval series. In patients with extrahepatic portal hypertension (Tables $4 a$ and 4b) Dean Warren's shunt is an excellent procedure and no comparison can be made with portocaval shunt, as in this disease the portal vein is thrombosed and not suitable for anastomosis.

When we consider delayed mortality and its causes, we see that there have been six late deaths in selective shunts as against nine late deaths in portocaval shunts (Table 5). In the selective shunt series all the late deaths except one were due to haematemesis after blockage of the shunt. However, in the portocaval shunt series, encephalopathy and liver cell failure were the cause of death in all these patients, all being cirrhotic, without exception.

The problem of encephalopathy is directly related to liver cell function and is easier to explain in cirrhotic patients where liver function is disturbed. In primary portal hypertension the liver is nearly normal and the incidence of encephalopathy is low compared with the cirrhotic patients (nine late deaths in cirrhotics due to encephalopathy as against none in primary portal hypertension).

We have had a better survival rate in primary portal hypertension after portocaval than splenorenal shunts (though statistically the results are not significant). It seems probable that portocaval shunt is a better shunt with low mortality and low incidence of encephalopathy, particularly when the splenic vein is diseased.

The children have fared better than the adult group. Out of eight live patients in the former 
Table 4a Comparison of Dean Warren's splenorenal, splenocaval, and portocaval shunt as elective and prophylactic procedure in cirrhosis

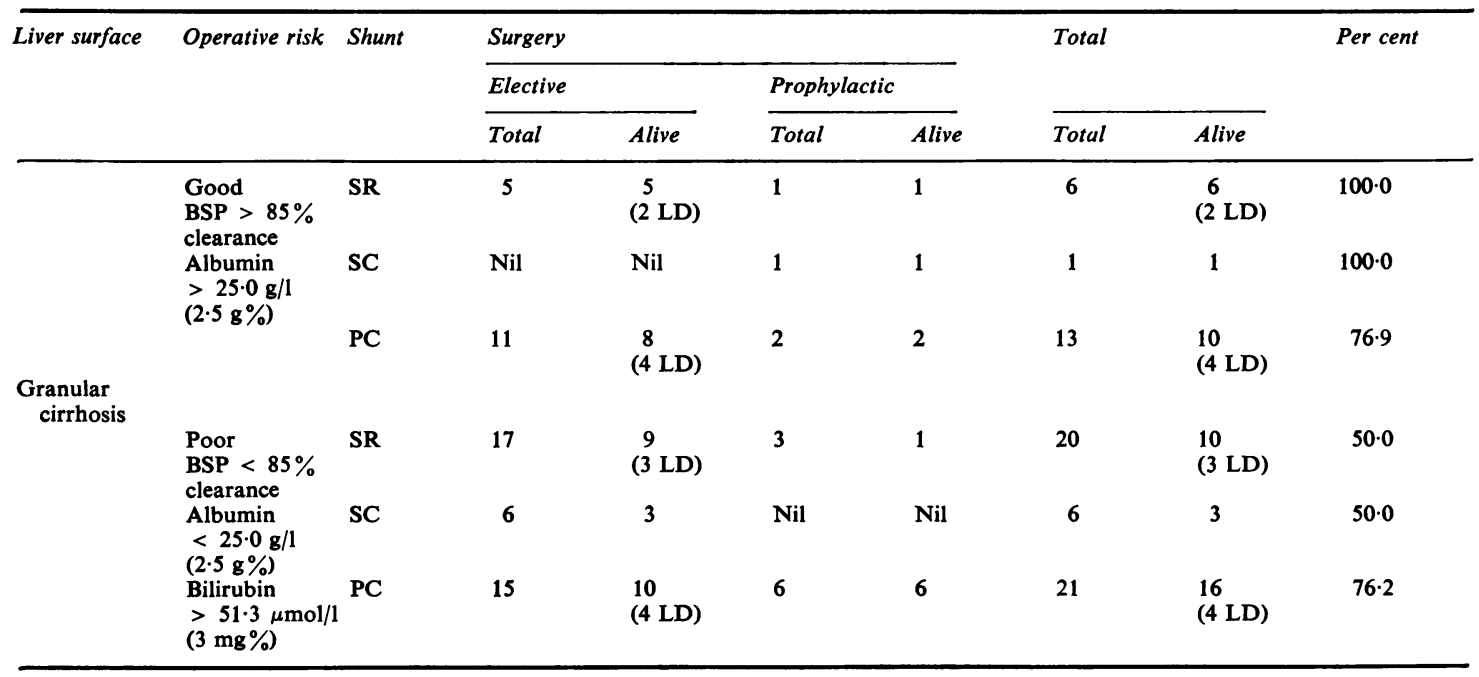

SR: splenorenal. SC: splenocaval. PC: portocaval. LD: late death.

Table 4b Comparison of Dean Warren's splenorenal, lienocaval, and portocaval shunts as elective and prophylactic procedure in primary portal hypertension

\begin{tabular}{|c|c|c|c|c|c|c|c|c|}
\hline \multirow{3}{*}{$\begin{array}{l}\text { Liver } \\
\text { surface }\end{array}$} & \multirow[t]{3}{*}{ Shunt } & \multicolumn{4}{|c|}{ Surgery } & \multirow{2}{*}{\multicolumn{2}{|c|}{ Total }} & \multirow[t]{3}{*}{ Per cent } \\
\hline & & \multicolumn{2}{|c|}{ Elective } & \multicolumn{2}{|c|}{ Prophylactic } & & & \\
\hline & & Total & Alive & Total & Alive & Total & Alive & \\
\hline $\begin{array}{l}\text { Smooth } \\
\text { primary } \\
\text { portal hyper- } \\
\text { tension }\end{array}$ & $\begin{array}{l}\text { SR } \\
\text { SC } \\
\text { PC }\end{array}$ & $\begin{array}{l}4 \\
9\end{array}$ & $\begin{array}{l}3 \\
(2 \mathrm{LD}) \\
4 \\
8\end{array}$ & $\begin{array}{l}1 \\
4 \\
1\end{array}$ & $\begin{array}{l}1 \\
4 \\
1\end{array}$ & $\begin{array}{r}6 \\
8 \\
10\end{array}$ & $\begin{array}{l}4 \\
(2 \mathrm{LD}) \\
8 \\
9\end{array}$ & $\begin{array}{r}66 \cdot 7 \\
100 \cdot 0 \\
90 \cdot 0\end{array}$ \\
\hline \multicolumn{9}{|c|}{ Extrahepatic obstruction: Dean Warren's splenorenal shunt only* } \\
\hline $\begin{array}{l}\text { Smooth } \\
\text { extra- } \\
\text { hepatic } \\
\text { obstruction }\end{array}$ & SR & 11 & 10 & 4 & 3 & 15 & 13 & $86 \cdot 7$ \\
\hline
\end{tabular}

*Portal vein and terminal splenic vein not available for anastomosis.

SR: splenorenal. SC: splenocaval. PC: portocaval. LD: late death.

Table 5 Late death: comparison between selective shunt and portocaval shunt

\begin{tabular}{|c|c|c|c|c|c|c|c|c|}
\hline \multirow[t]{2}{*}{ Operation } & \multicolumn{2}{|c|}{ Deaths } & \multicolumn{5}{|c|}{ Late deaths $(y r)$} & \multirow[t]{2}{*}{ Tota } \\
\hline & Total & Hospital & $0-1$ & 2 & 3 & 4 & 5 & \\
\hline \multirow{2}{*}{$\begin{array}{l}\text { Selective } \\
\text { shunt } \\
\text { Portocaval } \\
\text { shunt }\end{array}$} & 30 & 24 & 1 & 3 & 1 & 1 & - & 6 \\
\hline & 38 & 29 & 5 & 3 & 一 & 1 & - & 9 \\
\hline
\end{tabular}

group no patient has come back with rebleeding from varices, as against six out of 51 in the adult group.
The use of interrupted instead of continuous sutures for construction of the shunt in children has given us better results. The shunt size is quite big compared with the continuous suture employed for anastomosis and we feel that it allows for increase in the size of the shunt.

Ascites has posed several problems in the management of patients with portal hypertension. We have tried to overcome this problem with diuretics and sodium restriction during the postoperative period. Use of valvular incision with closure by stainless steel wire or monofilament nylon has prevented leakage from the suture line. 
We have had two unusual complications of selective splenorenal shunt. In one young girl (U.K.), in whom we had not ligated the ovarian vein, the reflux into the ovarian vein caused her troublesome menorrhagia, which was controlled with oral contraceptives. Another patient (B.D.) developed diabetes, which is now under control, the cause of which is still not clear.

Prophylactic shunt is a highly controversial subject. We advocate it in patients who have massive splenomegaly, in whom varices have been demonstrated radiologically, and who are seeking relief from the swelling. Splenectomy, which once was a standard treatment, has no logical basis, because it offers no protection from future gastrointestinal haemorrhage, as does a shunt which will reduce splenic size and at the same time offer permanent protection from gastrointestinal haemorrhage. In addition, in India we are faced with poor blood bank facilities and lack of trained personnel and medical centres.

Thus, in conclusion, in our hands portocaval shunt seems to have the edge over splenorenal shunt as an emergency and elective shunt procedure (though statistically the results are not significant). However, as seen by the absence of encephalopathy after selective splenosystemic shunt, it can be concluded that splenorenal shunt protects well against encephalopathy but offers poor protection against rebleeding from blockage of the shunt. The position is reversed in portocaval shunt: rebleeding as a result of blockage is very much less (probably because of the bigger size of the shunt) but it offers poor protection against encephalopathy.

A follow-up of splenocaval shunts for $1 \frac{1}{2}$ years has revealed a patent shunt with no rebleeding and no encephalopathy. We feel that this type of shunt has the haemodynamic advantage of end-to-side portocaval shunt, while at the same time achieving selective transplenic decompression by a much larger sized shunt. We are aware that it may not be feasible to perform this type of shunt in all patients.

Anatomically, the lienocaval shunt could be compared with end-splenic-to-end renal splenorenal shunt, in the sense that blood is delivered into the inferior vena cava directly, the only difference being interposition of the renal vein between the inferior vena cava and the splenic vein. We have operated on 20 patients where end-to-end splenorenal shunt was constructed and the mortality was $40 \%(12$ alive out of 20) as against mortality of $20 \%$ in lienocaval cases (12 alive out of 15).

Hence we conclude that splenocaval shunt is a superior selective shunt.

Thanks are due to Dr C. K. Deshpande, Dean, K.E.M. Hospital and Seth G. S. Medical College, Bombay, India, for permitting us to make use of the hospital records.

\section{References}

Thomford, N. R., Sirinek, K. R., and Martin, E. W., Jr. (1975). A series of 20 successful Warren shunts. Archives of Surgery, 110, 584-587.

Warren, W. D., Salam, A. A., Faraldo, A., Hutson, D., and Smith, R. B., III. (1972). End renal vein-to-splenic vein shunts for total or selective portal decompression. Surgery, 72, 995-1006.

Warren, W. D., Salam, A. A., Hutson, D., and Zeppa, R. (1974). Selective distal splenorenal shunt. Technique and results of operation. Archives of Surgery, 108, 306-314.

Warren, W. D., Zeppa R., and Fomon J. J. (1967). Selective trans-splenic decompression of gastro-oesophageal varices of distal splenorenal shunt. Annals of Surgery, 166, 437-455. 